\title{
THE EFFECT OF EXERCISE ON THE SIZE OF NORMAL HEARTS AND OF ENLARGED HEARTS OF DOGS
}

\author{
BY HAROLD J. STEWART \\ (From the Hospital of the Rockefeller Institute for Medical Research, New York)
}

(Received for publication February 6, 1929)

Although the changes in the heart produced by exercise have long been made the subject of investigation by clinicians and physiologists, the question has not yet been settled. The earliest view, formulated from clinical experience, was that when the heart was subjected to exertion it dilated. This opinion was derived from estimations of changes in the borders of the heart on percussion (T. Schott (1890) and Williams and Arnold (1899)). T. Schott (1897) was the first investigator to employ $\mathrm{x}$-ray examination in studying this problem. The data he collected appeared to support his view that dilatation of the heart occurred. Moritz (1908) in 1908 first demonstrated by means of orthodiagrams that acute cardiac enlargement did not follow over-exertion. Indeed, on the contrary, he found that in certain instances both in normal and pathologic hearts contraction took place. Since then, studies have been made of the effect of many varieties of exertion (swimming, rowing, running in marathon races) on the heart of man, from the point of view not only of discovering whether the heart reacts to acute exertion by dilating or contracting, but also of learning whether hypertrophy is necessarily a consequence of athletic training. More and more, the evidence which has been accumulated seems to indicate that dilatation does not occur as a consequence of acute exertion, but that on the contrary contraction in size takes place. Recently Gordon and Strong (1923) have studied in rabbits the effect of vigorous exercise on the size of the normal and abnormal heart. The hearts designated as abnormal were those in which enlargement resulted from repeated injections of spartein sulphate. According to these authors myocarditis was the resulting pathologic lesion. They found that the effect of exercise was the 


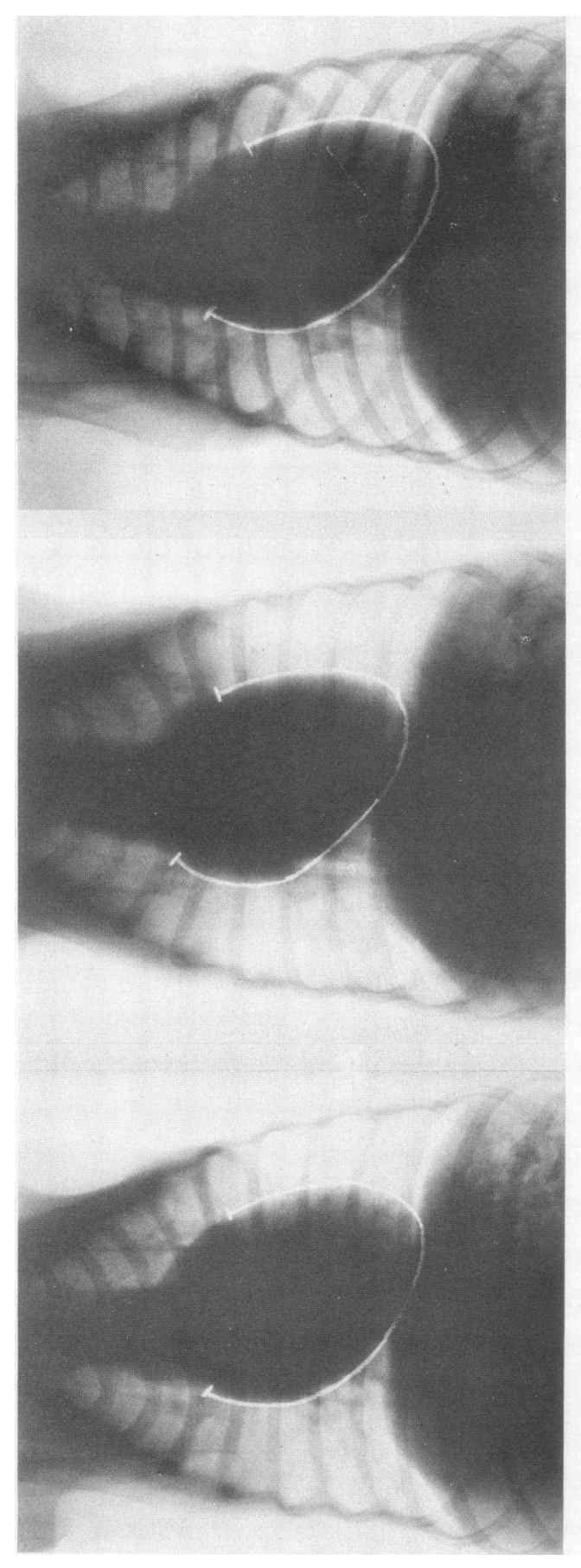

$$
\begin{aligned}
& \text { 家 }
\end{aligned}
$$

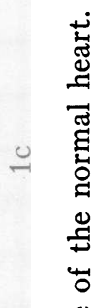

$$
\begin{aligned}
& \text {. ำ } \\
& \text { 폴 } \\
& \text { ธํํㅇ } \\
& \text { 虫 } \\
& \text { 递芯 } \\
& \text { 늉 } \\
& \text { 旡造 } \\
& \text { - } \\
& =. \\
& \text { 额 } \\
& \text { 욜 } \\
& \text { ㅎํ은 } \\
& \text { : } \\
& \text { 密䓠 } \\
& \text { 过 } \\
& \text { 긍 } \\
& \text { 원 } \\
& \text { ฮั้ } \\
& \stackrel{-10}{-1} \\
& \text { 苋 } \\
& \text { 임 } \\
& \text { 寻 } \\
& \text { 돓 } \\
& \text { - } \\
& \text { 点密 }
\end{aligned}
$$


same in both instances: a decrease in size of the hearts always occurred.

We have had an opportunity also to investigate this subject. For several years we have been engaged in attempting to find a method which would establish a state in dogs comparable to heart failure in man. One of the methods has consisted in the attempt to bring about this state by rendering the mitral valve insufficient. We have for this reason in our possession a number of dogs in which defects of the mitral valve have been made by operation and in which enlarged hearts have in consequence developed. They show no signs however of heart failure. It has been in connection with the study of the circulation of these dogs that we have investigated the response of the hearts to exercise. In them we are able to estimate the influence that valvular defect alone (presumably without disease of the muscle) exerts on the reaction of the heart to exertion. The form of exercise which we chose was running on a treadmill. We took the precaution of studying the effect of the same form of exertion on the hearts of normal dogs.' These experiments form the subject of this paper.

\section{'MATERIAL}

The subjects of certain experiments, as has been stated, were normal intact dogs. The dogs which were the subjects of other experiments were those which had been operated on 2 to $3 \frac{5}{6}$ years ago. Evidence of the lesions which were then created still existed at the time of the present experiments (table 1). Complete data concerning the operations will be published later (Stewart). A brief description only of the method used in operating on the valves need be given. Under ether anesthesia and under aseptic conditions the left auricular appendage was exposed and incised. A cardioscope ${ }^{1}$ was then inserted through this opening. By manipulation of the knife attached to the cardioscope the leaflets of the

1 The cardioscope which we used was designed with the assistance of Mr. R. Wappler, and was made for us by the Wappler Electric Company, Long Island City, New York. The idea of cutting the valves of the heart under direct vision was suggested to us by the preliminary report of Allen and Graham (1922). As complete data for the construction of their instrument was not available at the time, we devised this new instrument. The optical system is similar to that used in cystoscopes. We are much indebted to Doctors Graham and Allen for valuable aid in learning their methods and desire to express our thanks to them for their courtesy. 
TABLE 1

Effect of exercise on the size of the heart of normal dogs

\begin{tabular}{|c|c|c|c|c|c|c|c|c|c|}
\hline 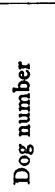 & Date & 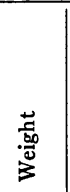 & 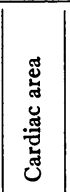 & 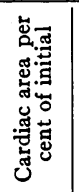 & 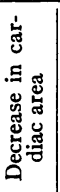 & 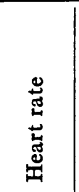 & 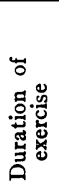 & 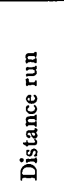 & $\begin{array}{l}\text { Time with reference to } \\
\text { running }\end{array}$ \\
\hline \multirow{4}{*}{235} & \multirow{4}{*}{ March 22, 1927} & $\mathrm{kgm}$. & $\begin{array}{c}s q . \\
c m .\end{array}$ & $\begin{array}{l}\text { per } \\
\text { cent }\end{array}$ & $\begin{array}{c}\text { per } \\
\text { cent }\end{array}$ & $\begin{array}{c}\text { per } \\
\text { minule }\end{array}$ & $\begin{array}{l}\text { min- } \\
\text { utes }\end{array}$ & miles & \\
\hline & & 15.2 & 60.4 & 100.0 & & 96 & & & Before \\
\hline & & & 57.3 & 94.8 & 5.2 & 120 & 45 & 0.9 & Immediately after \\
\hline & & & 56.1 & 92.8 & 7.2 & 128 & & & One hour after \\
\hline \multirow[t]{12}{*}{250} & \multirow[t]{3}{*}{ October 26,1927} & 10.5 & 35.8 & 100.0 & & 120 & \multirow{3}{*}{60} & \multirow{3}{*}{0.8} & Before \\
\hline & & & 34.4 & 96.1 & 3.9 & 110 & & & Immediately after \\
\hline & & & 34.9 & 97.5 & 2.5 & 130 & & & One hour after \\
\hline & \multirow[t]{3}{*}{ October 27, 1927} & 11.0 & 40.8 & 100.0 & & 120 & \multirow{3}{*}{60} & \multirow{3}{*}{1.1} & Before \\
\hline & & & 38.9 & 95.4 & 4.6 & 90 & & & Immediately after \\
\hline & & & 37.2 & 91.2 & 8.8 & 120 & & & One hour after \\
\hline & \multirow[t]{3}{*}{ October 28,1927} & 11.6 & 36.3 & 100.0 & & 120 & \multirow{3}{*}{60} & \multirow{3}{*}{1.3} & Before \\
\hline & & & 35.6 & 98.0 & 2.0 & 90 & & & Immediately after \\
\hline & & & 34.0 & 93.7 & 6.3 & 120 & & & One hour after \\
\hline & \multirow[t]{3}{*}{ October 29, 1927} & 10.3 & 37.9 & 100.0 & & 85 & \multirow{3}{*}{45} & \multirow{3}{*}{ * } & Before \\
\hline & & & 35.7 & 94.2 & 5.8 & 85 & & & Immediately after \\
\hline & & & 35.6 & 94.0 & 6.0 & 85 & & & One hour after \\
\hline \multirow[t]{3}{*}{251} & October 27,1927 & 12.7 & 48.8 & 100.0 & & 110 & \multirow{3}{*}{35} & \multirow{3}{*}{0.4} & Before \\
\hline & & & 46.1 & 94.5 & 5.5 & 90 & & & Immediately after \\
\hline & & & 46.1 & 94.5 & 5.5 & 115 & & & One hour after \\
\hline
\end{tabular}

* Speedometer not working.

TABLE 2

Enlargement of the heart following induction of artificial mitral insufficiency in dogs

\begin{tabular}{c|c|c|c|c|c}
\hline Dog number & $\begin{array}{c}\text { Area of heart } \\
\text { before operation }\end{array}$ & $\begin{array}{c}\text { Area of heart } \\
\text { after operation }\end{array}$ & $\begin{array}{c}\text { Time since } \\
\text { operation }\end{array}$ & $\begin{array}{c}\text { Increase in area } \\
\text { of heart }\end{array}$ & $\begin{array}{c}\text { Presence of } \\
\text { murmur at time } \\
\text { of running }\end{array}$ \\
\cline { 3 - 5 } 158 & sq. cm. & sq. cm. & years & per cent & \\
\cline { 5 - 6 } 161 & 46.4 & 84.4 & $3 \frac{5}{6}$ & 81.8 & + \\
171 & 46.0 & 72.3 & $2 \frac{1}{6}$ & 57.2 & + \\
153 & 50.3 & 68.9 & 2 & 37.7 & + \\
90 & 56.2 & 68.2 & $2 \frac{1}{6}$ & 21.3 & 0 \\
\hline
\end{tabular}


mitral valve were brought into view. The leaflets could then be cut under direct vision. Development of a marked systolic thrill was regarded as evidence that the operation had succeeded. The dogs completely recovered within 10 days to 2 weeks. The hearts began to increase in size after varying intervals of time. A loud systolic murmur persisted in each of the dogs (see exceptions, table 2). The dogs studied for the present purpose were in good health. They were trained to laboratory procedures and were not disturbed by them.

\section{METHODS}

The dogs were first trained to run on a treadmill. Certain dogs ran readily; others could not be induced to run and were not studied. After the preliminary training, the effect of running on the size of the heart was investigated by means of x-ray photographs of the heart. The x-ray photographs were made and measured according to the method described by Stewart (1927) for obtaining photographs of the hearts of dogs under uniform conditions. The anticathode was placed at a distance of 2 meters from the photographic film. A suture was inserted in the skin in the mid-line of the anterior chest wall at the level of the heart. The anti-cathode was always centered on this point before plates were exposed. Three $\mathrm{x}$-ray photographs were made during each session: the first, before the dog began running; the second, immediately after the dog had stopped running; and the third, after the dog had rested for one hour. Since the treadmill was not driven by a motor, but by the dogs themselves, they ran only as long as they did so voluntarily. They ran quite steadily for 25 to 60 minutes. The second photographs were made as soon as it was evident that the dogs did not wish to run longer. The tread was placed at an angle of 19 degrees with the horizontal and a speedometer recorded the number of revolutions from which the distance was calculated. Since the treadmill was in the $x$-ray room only a few seconds were required to transfer the dog from it to the dog board under the $x$-ray tube. The $x$-ray photographs were taken within 2 to 3 minutes after the dogs had stopped running. The rate of the heart was counted at the apex for one minute immediately after the photographs were taken. The observations were usually repeated several times in each dog.

The exposures were sufficiently long to photograph the diastolic heart shadow; in those photographs in which both systolic and diastolic positions of the heart could be identified, the diastolic area was the one measured.

\section{OBSERVATIONS}

Effect of exercise on the size of the heart in normal dogs. In dog 235 the initial cardiac area was $60.4 \mathrm{sq}$. cm. (table 2, fig. 1). It decreased to $57.3 \mathrm{sq} . \mathrm{cm}$. after the dog had been running for 45 minutes. After resting 1 hour it decreased still further to $56.1 \mathrm{sq} . \mathrm{cm}$. There was 
TABLE 3

The effect of exercise on the size of enlarged hearts in which systolic murmurs were still present

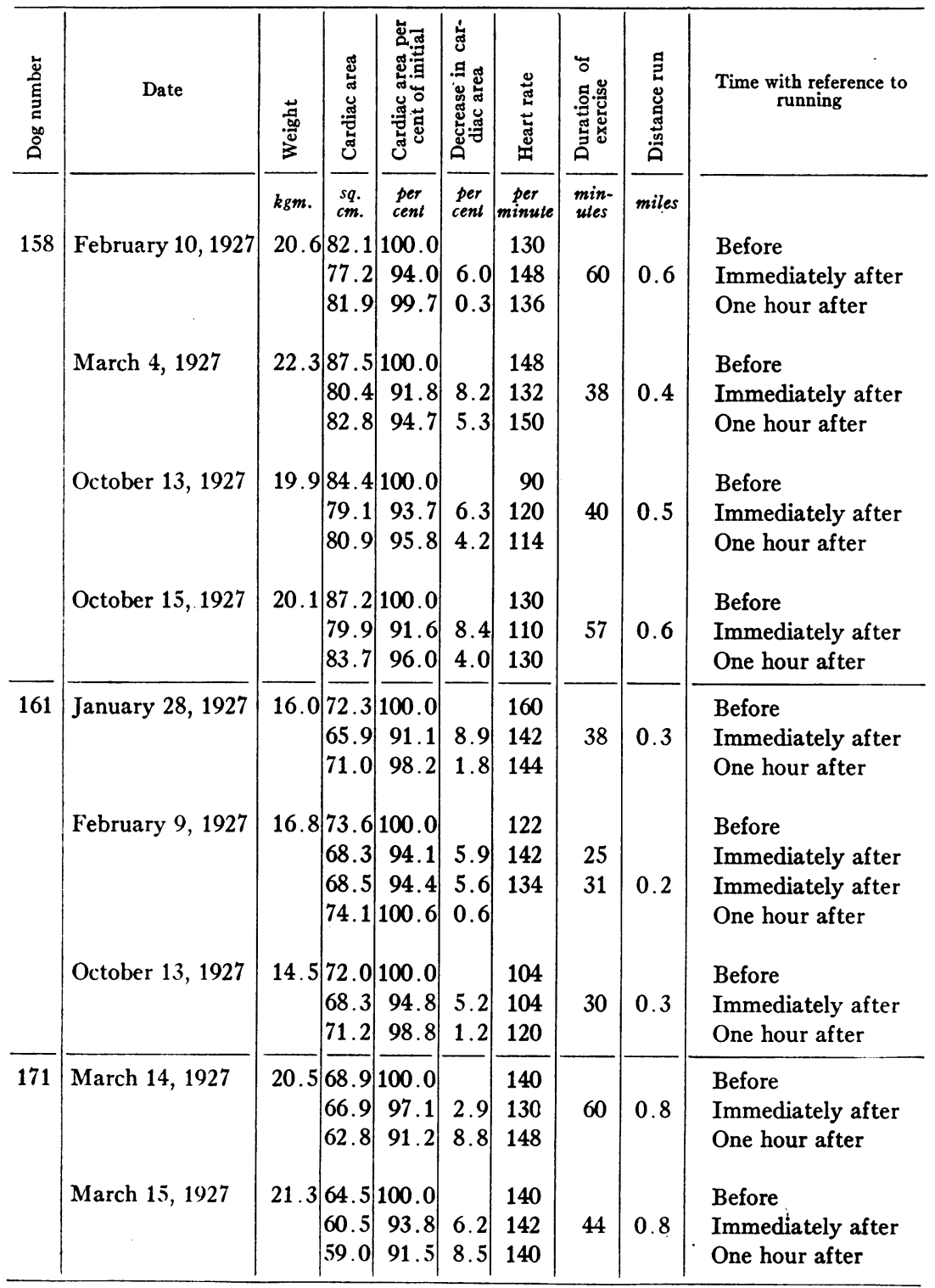




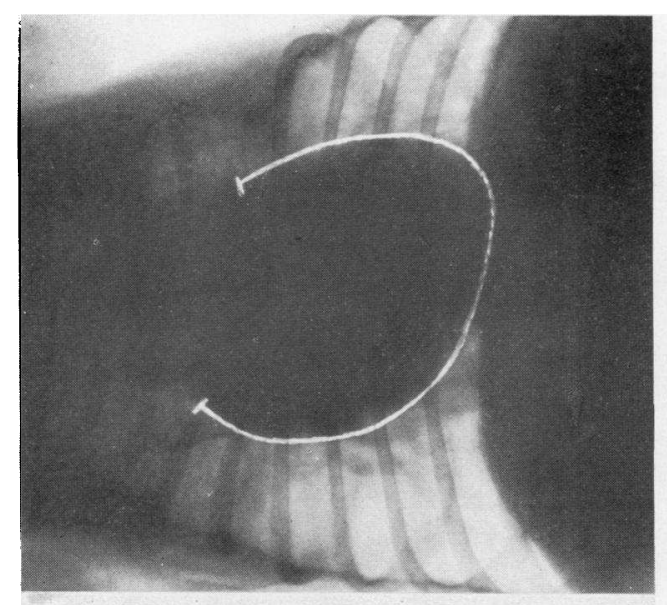

ปีّ

్ㅗㅀ

굥

.

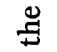

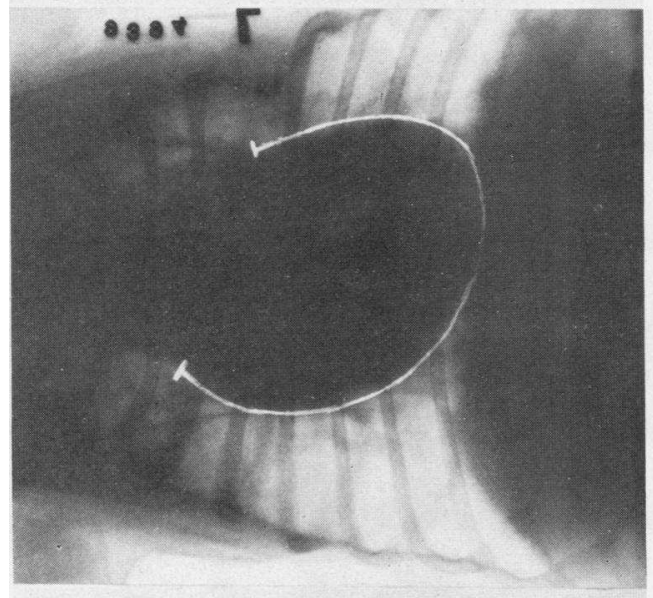

ธี

.

这

可

范

苞

प्व

풒

3.

तิ $\frac{-1}{0}$

.气ํㅀ

3

है

잉

옴

密

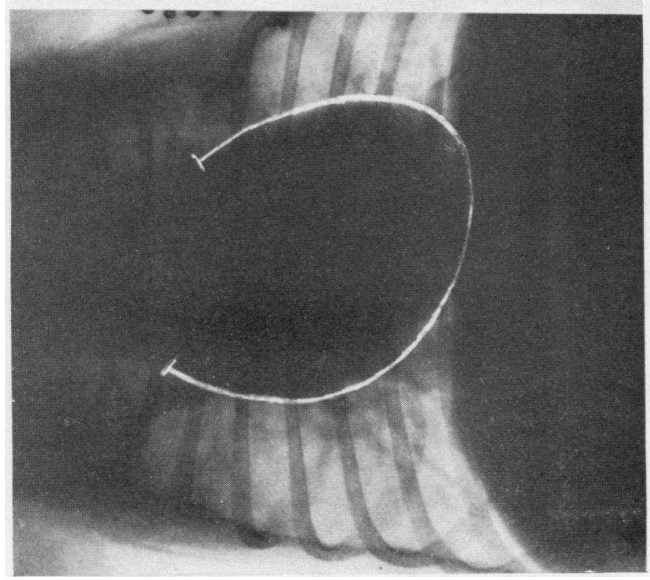

岗売

ఫुำ

్ㅠㅇ్ㅀ

范

원

ป

กึ

ง

灵

도 육

ㄱ.

空 苔 
accordingly a fall to 94.8 per cent of the initial size, followed by a further decrease to 92.8 per cent of the initial size one hour after exercise.

There are 4 observations on $\operatorname{dog} 250$ and one on dog 251 (Table 2). The results in all instances are similar to the one just reported. The size of the hearts decreased 3.9 to 5.8 per cent immediately after running, but decreased still further 6.0 to 8.8 per cent 1 hour later. In not a single instance did the size of the heart become greater than it had been in the beginning.

Effect of exercise on the size of enlarged hearts in which systolic murmurs are present. Mitral insufficiency was created in dog 158 on December 2, 1924, 35 years ago. During this time the area of the heart increased 81.8 per cent from $46.4 \mathrm{sq} . \mathrm{cm}$. to $84.4 \mathrm{sq} . \mathrm{cm}$. (table 2). This was the area on October 13, 1927 (table 3, fig. 2). After running 40 minutes on this day it decreased to 79.1 sq. cm., 93.7 per cent of the value before exercise. One hour later it was 80.9 sq. cm., 95.8 per cent of what it was before the start. There was then on this occasion a decrease of 6.3 per cent in the size of the heart after exercise. The dog ran on three other occasions. On these also the cardiac area decreased, the maximum decrease varying between 6.0 and 8.4 per cent.

Mitral insufficiency was created in dog 161 on December 11, 1924, $2 \frac{1}{6}$ years ago. During this time the area of the heart increased 57.2 per cent from $46.0 \mathrm{sq}$. cm. to $72.3 \mathrm{sq} . \mathrm{cm}$. (table 2). This was the cardiac area on January 28, 1927 (table 3). After running 38 minutes on this day it was 65.9 sq. $\mathrm{cm}$., that is to say, it had diminished 8.9 per cent. One hour later it was $71.0 \mathrm{sq}$. cm., approximating the size it was before the start. The dog ran on two other occasions. On these also a decrease in size of the heart occurred. The maximum decrease amounted to 5.9 per cent and 5.2 per cent respectively.

Mitral insufficiency was created in dog 171 on April 22, 1925, 2 years ago. During this time the heart had enlarged 37.7 per cent from $50.3 \mathrm{sq} . \mathrm{cm}$. to $68.9 \mathrm{sq} . \mathrm{cm}$. (table 2). He ran on the treadmill on two occasions. The decreases immediately after running were 2.9 and 6.2 per cent respectively and were 8.8 and 8.5 per cent respectively one hour later (table 3 ).

There are observations therefore on 3 dogs in which the heart was 
enlarged and in which there was still evidence that defects of the mitral valve (murmurs) were still present. In every instance the size of the heart decreased following the exercise of running on a treadmill.

Effect of exercise on the size of the heart in dogs subjected to operation but in which there was no longer evidence that valvular defect was present. Mitral insufficiency was created in dog 153 on November 20, 1924,

TABLE 4

Effect of exercise on the size of the hearts of dogs subjected to operation but in which systolic murmurs were no longer present

\begin{tabular}{|c|c|c|c|c|c|c|c|c|c|}
\hline 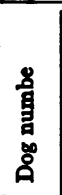 & Date & 蒂 & 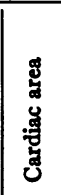 & 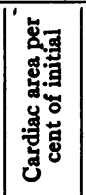 & 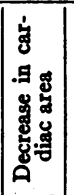 & 㤩 & 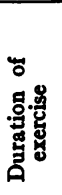 & 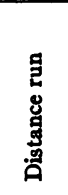 & $\begin{array}{l}\text { Time with reference to } \\
\text { running }\end{array}$ \\
\hline \multirow{4}{*}{153} & & kgm. & sq. & $\begin{array}{l}\text { per } \\
\text { cent }\end{array}$ & $\begin{array}{l}\text { per } \\
\text { cent }\end{array}$ & $\overline{\text { per }}$ & $\min _{\text {utes }}$ & miles & \\
\hline & January 18,1927 & 23.0 & $\begin{array}{l}69.6 \\
66.7 \\
62.9\end{array}$ & $\mid \begin{array}{r}100.0 \\
95.8 \\
90.4\end{array}$ & $\begin{array}{l}4.2 \\
9.6\end{array}$ & & 42 & 0.6 & $\begin{array}{l}\text { Before } \\
\text { Immediately after } \\
1 \text { hour after }\end{array}$ \\
\hline & January 22, 1927 & 23.0 & $\begin{array}{l}67.8 \\
60.9 \\
67.9\end{array}$ & $\begin{array}{r}100.0 \\
89.0 \\
100.0\end{array}$ & 11.0 & $\begin{array}{l}182 \\
145 \\
170\end{array}$ & 55 & 0.6 & $\begin{array}{l}\text { Before } \\
\text { Immediately after } \\
1 \text { hour after }\end{array}$ \\
\hline & January 25,1927 & 23.0 & $\begin{array}{l}68.2 \\
62.5 \\
67.5\end{array}$ & $\begin{array}{r}100.0 \\
91.5 \\
99.0\end{array}$ & $\begin{array}{l} \\
8.5 \\
1.0\end{array}$ & $\begin{array}{l}165 \\
170 \\
155\end{array}$ & 50 & 0.4 & $\begin{array}{l}\text { Before } \\
\text { Immediately after } \\
1 \text { hour after }\end{array}$ \\
\hline 90 & April 15, 1927 & 11.5 & $\begin{array}{l}42.6 \\
40.2 \\
42.6\end{array}$ & $\begin{array}{r}100.0 \\
94.3 \\
100.0\end{array}$ & 5.7 & $\begin{array}{l}130 \\
120 \\
112\end{array}$ & 38 & 0.8 & $\begin{array}{l}\text { Before } \\
\text { Immediately after } \\
1 \text { hour after }\end{array}$ \\
\hline
\end{tabular}

$2 \frac{1}{6}$ years ago. During this time the size of the heart increased 21.3 per cent, from $56.2 \mathrm{sq}$. cm. to $68.2 \mathrm{sq}$. cm. (table 2). A systolic murmur was heard for some months after operation but later it disappeared. It was not heard at the time of these experiments. The dog ran on three occasions. On each occasion the heart was smaller after running than it had been in the beginning (table 4). It decreased 8.5 per cent on the first, 11 per cent on the second and 4.2 per cent on the third occasion. One hour later it had nearly regained its 
initial size on the first, it had returned to its initial size on the second, and decreased still further ( 9.6 per cent) on the third occasion.

Mitral insufficiency was created in dog 90 on February 28, 1924. A soft systolic murmur was heard for some months after operation but later it disappeared. Three and one sixth years after operation the area of the heart was approximately the same as before operation (0.8 per cent decrease) (table 2). The area of the heart was 42.6 sq. $\mathrm{cm}$. on April 15, 1927 (table 4). After running on the treadmill for 38 minutes it was $40.2 \mathrm{sq}$. cm., that is to say, a decrease of 5.7 per cent had occurred. The initial size was regained one hour later.

In one dog ( 3 occasions) then the subject of an artificially enlarged heart and in a second in which there was no enlargement, the hearts decreased in size after running on a treadmill. The maximum decrease was 11 per cent. A systolic murmur was not heard in either case.

Effect of exercise on the heart rate. The heart rate decreased after running in 2 normal dogs (dog 250, 3 occasions and dog 251, once) (table 2), unchanged once (dog 250) and increased once (dog 235). In the case of the dogs in which the hearts' were enlarged, the rate sometimes decreased (dog 158 twice, dog 161 once, dog 171 once, dog 90 once, and dog 153 once), sometimes increased (dog 158 twice, and $\operatorname{dog} 161$ once) and was sometimes unchanged (dog 161 once, dog 171 once, and dog 153 once). It is clear that the same effect was not always observed even in the same dog.

\section{DISCUSSION}

We have presented data showing that the hearts of normal dogs decrease in size following exercise. Decrease in size also occurred in hearts that were enlarged, whether the valve defect (murmur) was or was not still present. The effect in dogs in which the hearts were enlarged was the same as in the normal hearts; the dogs were all in good health and exhibited no evidence of heart failure. Although the mitral valves had been subjected to damage and the hearts had enlarged in consequence of this injury, there had occurred no disease of the heart muscle so far as is known. Although the decrease in size was small, 3.9 to 11 per cent, it is nevertheless significant and it occurred consistently. Enlargement never was observed. In the hour after exercise the hearts sometimes decreased still further in size 
(if the decrease in the first instance was small), sometimes remained unchanged and at other times regained their initial size. We have no explanation to offer for this difference. The changes which we observed in dogs were not as great as those observed in rabbits by Gordon and Strong (1923). The difference in the results obtained is probably due to the fact that the rabbits ran until completely exhausted, while our dogs ran only as long as they did so voluntarily. The distance which the dogs ran may appear to be small. The average distance was 0.6 mile, but the inclination of the tread $\left(19^{\circ}\right)$ necessitated a vertical ascent of $1000 \mathrm{ft}$. in this distance.

We cannot be certain of the factors responsible for the occurrence of the decrease in size of the hearts of these dogs after exercise. It was observed also to accompany regular tachycardia (Stewart and Crawford, 1927). Decreased filling of the heart in the shortened diastole may be one of the factors. In the case of these experiments however tachycardia was not a factor, since the ventricular rate exhibited no consistent change, remaining unchanged or becoming either slower or faster than the initial rate. Increase in size of the vascular bed may of course have taken place due to the opening of channels which were hitherto closed, for exercise may be believed to be the occasion for the opening of a greater number of capillaries in the muscles and skin than when the animals are in a resting state. The blood would then be drained away from the heart.

Both Meek and Eyster (1922) and Stewart (Stewart, a) have shown that the size of the heart decreases when the volume of circulating blood is diminished. But decrease in volume of blood was in all probability not a factor in these cases since Hastings (1921) has shown an increase following exercise in the hemoglobin content (expressed as oxygen capacity) of the blood and Broun (1922) has demonstrated an actual increase in the total blood volume.

In another connection also there is similarity in behavior of large and small hearts. The same dogs which served in these experiments were utilized also in studying the effect of digitalis. In both groups decrease in cardiac size, decrease in cardiac output and increase in ventricular excursion followed the administration of this drug (Cohn and Stewart, 1928a and 1928b).

It is not certain how far an application can be made of the data of 
these experiments to cases of heart disease in man. The analogy is not close enough to warrant the conclusion that acute exercise is not harmful to patients suffering from valvular disease when they exhibit no signs of heart failure. It is infrequent that one finds in patients the conditions which were present in these experiments, that is to say, valvular insufficiency and cardiac enlargement without concomitant disease of the myocardium.

\section{SUMMARY}

The effect of running on a treadmill on the size of the hearts of dogs has been studied. It was found that the size of both normal and enlarged hearts always decreased.

\section{CONCLUSIONS}

Dilatation of the heart does not occur in normal dogs following voluntary exercise. On the contrary, the size of the heart decreases. When dogs in which the heart is enlarged in consequence of artificially created valvular defects, but in which there is presumably no myocardial disease, and in which there are no signs of heart failure, are subjected to exercise, the size of the heart likewise decreases.

\section{BIBLIOGRAPHY}

Allen, D. F., and Graham, E. A., J. Am. Med. Assoc., 1922, lxxix, 1028. Intracardiac Surgery-A New Method. Preliminary Report.

Broun, G. O., J. Exper. Med., 1922, xxxvi, 481. Blood Destruction During Exercise. I. Blood Changes Occurring in the Course of a Single Day of Exercise.

Cohn, A. E., and Stewart, H. J. (1928a), J. Clin. Invest., 1928, vi, $79 . \quad$ The Relation Between Cardiac Size and Cardiac Output per Minute Following the Administration of Digitalis in Dogs in Which the Heart is Enlarged.

Cohn, A. E., and Stewart, H. J. (1928b), J. Clin. Invest., 1928, vi, 53. The Relation between Cardiac Size and Cardiac Output per Minute Following the Administration of Digitalis in Normal Dogs.

Gordon, B., and Strong, G. F., Arch. Int. Med., 1923, xxxii, 517. Studies on the Rabbit's Heart. II. Effect of Vigorous Exercise on the Size of the Normal and the Abnormal Heart.

Hastings, A. B., Public Health Bulletin No. 117. May, 1921. Treasury Department U. S. Public Health Service, Wash., Govt. Printing Office, 1921. The Physiology of Fatigue. Physico-chemical Manifestations of Fatigue in the Blood. 
Meek, W. J., and Eyster, J. A. E., Am. J. Physiol., 1922, lxi, 186. The Effect of Plethora and Variations in Venous Pressure on Diastolic Size and Output of the Heart.

Moritz, F., Münch. med. Wchnschr., 1908, lv, 713. Ueber funktionelle Verkleinerung des Herzens.

Moritz, F., Münch. med. Wchnschr., 1908, lv, 1331. Zur Frage von akuten Dilatation des Herzens durch Ueberanstrengung.

Schott, T., Verhand. d. Congr. f. inn. Med., 1890, ix, 448. Zur acuten Ueberanstrengung des Herzens und deren Behandlung.

Schott, T., Deutsch. med. Wchnschr., 1897, xxiii, 495. III. Experimente mit Röntgenstrahlen über acute Herzüberanstrengung.

Stewart, H. J., Experiments to be published.

Stewart, H. J., Arch. Pathol., 1929, vii, 767. (a) A Study of Certain Effects Occasioned in Dogs by Diphtheria Toxin. II. An Analysis of the Mechanisms possibly Responsible for the Alterations of the Heart.

Stewart, H. J., J. Clin. Invest., 1927, iii, 475. A Technique for measuring X-ray Photographs of the Cardiac Areas of Dogs.

Stewart, H. J., and Crawford, J. Hamilton, J. Clin. Invest., 1927, iii, 483. The Effect of Regular and Irregular Tachycardias on the Size of the Heart.

Williams, H., and Arnold, H. D., Phila. Med. J., 1899, iii, 1233. The Effects of Violent and Prolonged Muscular Exercise upon the Heart. 